\section{Ocular motor abnormalities in neurodegenerative disorders}

CA Antoniades and C Kennard
Nuffield Department of Clinical Neurosciences, University of Oxford, Oxford UK

Correspondence: CA Antoniades, Nuffield Department of Clinical Neurosciences, University of Oxford, Level 6, West Wing, John Radcliffe Hospital, Headley Way, Headington, Oxford OX3 9DU, UK. E-mail: chrystalina. antoniades@clneuro.ox.ac.uk

Received: 9 September 2014

Accepted in revised form: 10 October 2014

Published online: 21

November 2014

The paper was presented by Professor Kennard at the Cambridge Ophthalmological Symposium 2014.

\begin{abstract}
Eye movements are a source of valuable information to both clinicians and scientists as abnormalities of them frequently act as clues to the localization of a disease process. Classically, they are divided into two main types: those that hold the gaze, keeping images steady on the retina (vestibulo-ocular and optokinetic reflexes) and those that shift gaze and redirect the line of sight to a new object of interest (saccades, vergence, and smooth pursuit). Here we will review some of the major ocular motor abnormalities present in neurodegenerative disorders. Eye (2015) 29, 200-207; doi:10.1038/eye.2014.276; published online 21 November 2014
\end{abstract}

Neurodegenerative disorders are chronic conditions of the central nervous system that often lead to motor problems and dementia. With an ageing population, we are facing a rise in the incidence of these conditions. Studies have revealed that neurodegenerative conditions, including Alzheimer's disease (AD), Parkinson's disease (PD), and Huntington's disease (HD) have a presymptomatic phase that may be present for some years before the onset of the overt clinical syndrome. During this presymptomatic phase, considerable neuronal degeneration occurs; but the potential opportunity for preventative intervention is lost, because the diagnostic symptoms and signs have not yet appeared. Once the condition is manifest, there may still be diagnostic uncertainty, particularly in disorders such as PD, which is closely mimicked by the early stages of the so-called 'Parkinson's-plus' conditions.

Eye movement control is complex and involves many brain areas, including the brainstem, cerebellum, basal ganglia, and cerebral cortex. ${ }^{1}$ Abnormalities of eye movements are a source of valuable information to clinicians and scientists. Identification of an abnormality during clinical examination may allow accurate localisation of a focal lesion in the nervous system, and may give clues as to the nature of the pathology causing it. Certain eye movement abnormalities may also reflect the presence of widespread disease affecting far more than just the ocular motor system, for example, the inability to voluntarily elevate the eyes seen in progressive supranuclear palsy (PSP). Oculometry-using sophisticated measuring instruments rather than simple clinical examination-has been increasingly used as an experimental tool to gain insights into a wide range of neurological disorders. ${ }^{2-5}$

\section{Alzheimer's disease (AD)}

\section{Clinical ocular motor manifestations}

Abnormalities of eye movements in AD, especially saccades, have been reported in a number of studies. ${ }^{6}$ Hypometric saccades, prolonged saccade latencies, ${ }^{7-11}$ reduced peak velocities, ${ }^{8}$ and disorganized visual scanning ${ }^{10,12}$ have been noted. However, an early observation suggesting that prosaccadic latencies might prove to be a reliable index of dementia severity ${ }^{13}$ was not confirmed. ${ }^{7}$ Furthermore, results from studies looking at the saccadic gain and velocity in $\mathrm{AD}$ are controversial; some studies found impairment, 8,14 whereas other studies did not., 9,15

\section{Research findings}

Scinto et al ${ }^{16}$ noted deficits in the generation of visually-guided saccades in $\mathrm{AD}$, which they attributed to an attentional, rather than to an ocular motor source. However, two consistent impairments of saccades have emerged from AD research: (1) a high frequency of saccadic 
intrusions during attempted fixation; ${ }^{11}$ and (2) visual capture by the target in the antisaccadic paradigm, ${ }^{14,17-19}$ in which the subject has to suppress a reflexive saccade to a peripheral target and execute an endogenously driven saccade to an equal and opposite location. Interestingly, inhibition errors in the antisaccadic paradigm could be predicted by measures of dementia severity. ${ }^{14,17,18,20}$ Antisaccades may provide not only a functional index of the dorsolateral prefrontal cortex, which is damaged in the later stages of $\mathrm{AD}$, but also a tool for monitoring the progression of AD. ${ }^{6}$ A more recent study ${ }^{21}$ used an antisaccadic paradigm as a way of testing inhibitory control in AD patients. The results showed that AD patients were impaired relative to the mild cognitive impairement in participants and healthy controls. The antisaccadic task, therefore, might be a useful and relatively easy way of measuring executive function in AD.

Smooth pursuit eye movements in AD are also usually abnormal. Increased frequency of saccades during pursuit $^{22}$ may result from a disturbance in the pursuit system, due to a reduced gain (eye velocity divided by target velocity). ${ }^{23}$ However, large-amplitude saccadic intrusions in the direction of target motion are also observed, probably reflecting increased saccadic distractibility.

Recently, a study by Kapoula et a ${ }^{24}$ has looked into measuring fixational eye movements and in particular microsaccades, in a group of $\mathrm{AD}$, minimal cognitive impairment, and healthy individuals. Microsaccade direction differed significantly in patients $v s$ controls, but no abnormalities were observed in microsaccade dynamics (such as duration, intersaccadic intervals, peak velocity, and the peak duration-magnitude relationship) that are more directly related to the function of the brainstem saccade generator. ${ }^{25}$ Such studies lend support to the idea that microsaccadic metrics may be a useful tool for an accurate diagnosis, as well as for evaluating ongoing therapies in neurodegenerative disorders, such as AD.

\section{Frontotemporal dementia (FTD)}

\section{Clinical manifestation}

The majority of patients with FTD develop the condition in the presenium, with the onset usually occurring between 45 and 60 years of age. ${ }^{26}$ About $50 \%$ of patients have a positive family history in a first-degree relative. An abnormality of chromosome 17 was present in affected members of a family with an autosomal dominant form of the disease. ${ }^{27}$ The incidence of FTD in relation to presenile $\mathrm{AD}$ is estimated to be at least $1: 5$. FTD comprises three core clinical dementia syndromes, a behavioural and dysexecutive (or frontal) variant called frontotemporal lobar dementia and two forms of primary progressive aphasia, a temporal lobe variant, also called semantic dementia (SD), and a progressive nonfluent aphasia (PA). ${ }^{28}$ The diagnosis of each of these FTLD clinical syndromes relies mainly on the combination of progressive behavioural and neuropsychological impairments and the exclusion of others.

\section{Research findings}

Studies of saccades in FTD have found normal reflexive saccades, but impairment in the ability to inhibit a reflexive saccade in the antisaccade task, that is, impaired reflexive saccade inhibition, except in the SD group..$^{29,30}$ However, they were able to self-correct the antisaccade errors as well as controls, in contrast to patients with AD, corticobasal degeneration (CBD), and PSP. Interestingly there was a positive correlation between antisaccade performance and the volume of a segment of the right frontal eye field using an unbiased voxel-based morphometric analysis of grey matter volume in their structural MRI images. ${ }^{30}$ Findings in a recent study have shown that saccades are abnormal in FTD, reflecting reduced decision-making speed, and that these abnormalities related to atrophy of the left frontal eye field. In addition, patients with FTD had an increased incidence of early saccades, which may be due to reduced inhibition of primitive responses. ${ }^{31}$

Although FTLD, CBD, and PSP might present with similar pathology, they do represent distinct syndromes. ${ }^{32}$ The results of the ocular motor studies so far suggest that saccadic analysis may be useful in differentiating these groups (saccadic gain and velocity, and antisaccade performance). ${ }^{19,33}$

\section{Dementia with lewy bodies (DLB)}

\section{Clinical manifestation}

DLB is now recognized as one of the most common dementias in the elderly after AD. It can be recognized on the basis of several clinical characteristics including progressive dementia with marked slowing and fluctuations, persistent visual hallucinations, and an extrapyramidal syndrome. Several other clinical and imaging features are highly suggestive, such as the presence of rapid eye movement sleep disorder, severe sensitivity to neuroleptics, and specific neuroimaging abnormalities.

\section{Ocular motor manifestations}

\section{Research findings}

In a comparison of saccades in patients with $A D, D L B$ and PD dementia (PDD), and controls, those with DLB 
and PPD were impaired in both reflexive saccade execution (gap and overlap latencies) and complex saccade performance (target prediction, error decisions, and antisaccades errors). ${ }^{19}$ Patients with AD were only impaired in complex saccade performance, but not reflexive saccade execution. Impaired saccade execution in reflexive tasks allowed discrimination between DLB vs AD. It was concluded that impairments in reflexive saccades may be helpful for differential diagnosis and are minimal when either cortical (AD) or nigrostriatal neurodegeneration (PD) exists solely; however, they become prominent with combined cortical and subcortical neurodegeneration in PDD and DLB. The similarities in saccade performance in PDD and DLB underline the overlap between these conditions and underscore differences between $\mathrm{AD}$ and PD. ${ }^{12}$

\section{Basal ganglia disorders}

The basal ganglia have a vital role in the generation of saccades and it is not surprising that many of the diseases of the basal ganglia give rise to disturbances of saccades.

\section{Parkinson's disease}

Idiopathic PD (IPD) is a progressive neurodegenerative disorder that results in a loss of dopamine in the basal ganglia giving rise to tremor, rigidity, bradykinesia, and postural instability.

\section{Clinical ocular motor findings}

Ocular motor abnormalities that might be detected during a routine clinical examination include blepharospasm, paucity of blinking, apraxia of lid opening, visual neglect, reduced vergence, reduced upgaze, and blurred vision. ${ }^{34}$

\section{Research findings}

Abnormalities of eye movements, especially in saccades are known to occur in PD. To date, several studies have presented quantitative data from studying different types of saccadic eye movements in PD, but early results were conflicting. Although some authors found that saccadic velocity was preserved, ${ }^{35,36}$ others did not. ${ }^{37,38}$ As pointed out, ${ }^{36}$ these discrepancies could have been attributed to methodological differences. In most studies, the patients were taking various antiparkinsonian drugs that we now know may have profound effects on eye movements.

Typically, even at the earlier stages of the disease, the most consistent ocular motor abnormality in PD is saccadic hypometria in which the primary saccade undershoots the target, especially vertically. ${ }^{39-41}$ This was initially demonstrated in saccades executed to verbal command, ${ }^{42}$ in the dark, ${ }^{43}$ or to fixed targets. ${ }^{37}$ Predictive saccades also show hypometria, in addition to difficulty in anticipating the stimulus, ${ }^{36,44}$ and in unilaterally affected patients the abnormalities were found to be lateralized. ${ }^{45}$ There are also deficits in initiation and performance of internally mediated tasks, including antisaccades and memory-tasks. ${ }^{40,44,46-48}$ The memoryguided task seems to be the most sensitive, and performance gets worse as disease progresses. ${ }^{46,47,49-51}$ Mild to moderate PD patients show a marked increase in saccade amplitudes. ${ }^{52}$ Saccadic latency is typically normal or mildly increased compared with controls. ${ }^{36,38,53}$

Studies of scanpaths of saccades during visuospatial sorting tasks have provided insights into the cognitive changes in PD. ${ }^{4}$ In the 'Tower of London' task, that tests working memory and planning, patients have to rearrange coloured balls to fit a particular pattern. After analysing the scanpaths of PD patients in this task compared with those of controls, it was suggested that PD patients kept forgetting the arrangement of the test objects, ${ }^{54}$ implying a deficiency in their spatial working memory. ${ }^{55}$

Advanced PD patients may show greater abnormalities on particular tests as compared with mild PD patients. ${ }^{5}$ For example, they make more directional errors in the antisaccade task and have increased mean latencies ${ }^{53}$ that increase as the disease progresses; ${ }^{48}$ this is more evident when patients are on anticholinergic medication. ${ }^{56}$ It has been suggested that in advanced PD, brain structures other than the basal ganglia such as the frontal lobe, ${ }^{57}$ might produce these saccadic deficits.

If endogenously and exogenously driven saccades are differentially affected in PD, a task such as the antisaccade paradigm that involves both should demonstrate impairment. Some studies have found no significant impairment in the performance of PD patients compared with age-matched controls, ${ }^{47,58}$ and others have shown impaired performance. ${ }^{48,53,56,59,60}$ It is difficult to draw firm conclusions from these studies because of methodological difficulties; however, the one study that employed a 'gap' paradigm and tested patients in their 'OFF' state, demonstrated more errors, increased latency, and reduced gain in patients with mild to moderate $\mathrm{PD},{ }^{59}$ compared with controls. However, if reflexive (pro-) and antisaccade tasks are mixed up in a block, as opposed to the usual single-task blocks normally used, then PD patients showed a marked increase in prosaccade and antisaccade error rates in repeated trials. ${ }^{61}$ 


\section{Response to treatment}

Studies looking into the effect of L-dopa are not consistent and sometimes even conflicting, which may be owing to an inadequate number of subjects studied.

A few studies have shown beneficial effects on the parameters of voluntary saccades, ${ }^{39,42}$ and on the ability to perform sequences of MGS, ${ }^{49}$ but none has ever demonstrated any improvement in the most characteristic abnormality in PD, the hypometria of MGS. Recent studies have agreed that L-dopa and dopamine agonists shorten the latency of these voluntary saccades, ${ }^{62,63}$ whereas they prolong the latency of both externally guided or triggered saccades. ${ }^{64}$

Several studies have examined the effect of STN stimulation on saccades. Stimulation of the STN reduced reflexive saccadic latencies, ${ }^{3,65}$ increased the amplitude, ${ }^{66,67}$ and produced a marked improvement in the gain of MGS. ${ }^{68}$ There is also a single case report of a similar improvement in MGS, as well as antisaccades, in a patient with a GPi electrode when the stimulator is turned on. ${ }^{69}$ Depending on the location of the electrode fixation instability may occur. ${ }^{70}$ A disruption of ocular fixation has also been reported after a unilateral pallidotomy. ${ }^{71}$

\section{Differential diagnosis}

Clinically obvious impairment in vertical eye movements is a characteristic of PSP, although it may be seen in other conditions such as diffuse Lewy body disease, ${ }^{8} \mathrm{CBD},{ }^{72}$ amyotrophic lateral sclerosis, ${ }^{73}$ post-encephalitic parkinsonism, ${ }^{74}$ and Creutzfeld-Jacob disease. ${ }^{75}$ In PSP, slowing of vertical saccades precedes ophthalmoplegia and is probably the earliest sign of ocular motor involvement. A supranuclear gaze palsy may be seen in CBD, but usually only when the disease is advanced. ${ }^{76}$

Eye signs are rarely an early feature of MSA, but in some cases may mimic PD.

Several studies are using eye movements to differentiate parkinsonian-like syndromes, although it is still not clear to what extent eye movement recordings are helpful in discriminating among them. A couple of small studies have examined simple saccadic metrics in the horizontal, vertical, and diagonal planes in patients with PD, MSA, pure akinesia, PSP, ${ }^{77}$ and CBD. ${ }^{41}$ It was found that compared with age-matched controls only patients with PSP had slow saccades (in any direction), and only patients with CBD had increased saccadic latency. Other parameters such as hypometria, vestibuloocular responses, and smooth pursuit did not discriminate between groups, although deviation of oblique saccades towards the horizontal plane was more marked in patients with pure akinesia and PSP.
In another study, 58 patients with CBD had greater saccadic latency, and those with PSP more marked hypometria and worse antisaccade performance compared with patients with PD, however, there were no saccadic criteria by which patients with MSA could be differentiated from those with PD. Thus detailed eye movement analysis may be helpful in identifying patients with PSP and possibly CBD, but until there is more data on its sensitivity and specificity using large prospectively studied patient cohorts, it is difficult to recommend it for routine use in the diagnosis of parkinsonian disorders.

\section{Huntington's disease (HD)}

HD is a neurodegenerative disorder, due to an inherited autosomal dominant genetic mutation, characterized by chorea, cognitive impairment leading to dementia, and psychiatric disturbances with a clinical onset in the 30s.

\section{Clinical ocular motor findings}

For HD, the challenge is to predict disease onset given that we can test for the presence of the abnormal huntingtin gene on chromosome 4. Ocular motor impairment is among the first manifestations in $\mathrm{HD}^{78}$ and the main abnormality involves the saccadic system to a greater extent than the pursuit system. This has been attributed to the close involvement of the basal ganglia with the saccadic control circuit. ${ }^{79,80}$

\section{Research findings}

Impairment of both vertical and horizontal saccades was originally reported in patients suffering from manifest HD. ${ }^{81}$ Contrary to earlier eye movement findings on premanifest HD individuals that reported intact performance, $^{82,83}$ a number of recent studies have reported deficits even in premanifest subjects. Initiation deficits of voluntary guided saccades, saccadic slowing, and delayed reflexive saccades were present. ${ }^{84-86}$ When compared with controls, premanifest individuals also show impairment in the antisaccadic and memoryguided tasks and longer latencies, especially during the latter. Furthermore, the saccadometry research tool has proved valuable in separating premanifest, manifest, and controls who showed an increased incidence of early saccades with unusually short latencies. ${ }^{84-89}$

Manifest patients early in the course of their disease, exhibit reduced saccadic velocity, ${ }^{78,81,90}$ impaired initiation of saccades, an increase in the frequency of square-wave jerks, and an increase in saccadic latencies, that is greater for voluntary than reflexive saccades. They have excessive distractibility during attempted fixation, 
even when specifically instructed to maintain fixation on a centrally located target. ${ }^{78,91} \mathrm{HD}$ patients also increased distractibility in the antisaccade task. ${ }^{91,92}$ Impaired initiation of saccades was manifested by increased latency and the inability to make a saccade without head thrust or blink. ${ }^{78}$ This behaviour is similar to that of patients with congenital ocular motor apraxia. Volitional saccades are also often hypometric. ${ }^{84,93,94}$ In addition, saccadic hypometria has been documented in mildly affected HD patients. ${ }^{78,91-93,95-99}$

Later on in the disease, manifest patients usually begin to show more prominent slowing of saccades, as well as smooth pursuit deficits. Eventually, a reduced range of eye movements is observed with vertical saccades affected more than horizontal ones. 5,78,96 Patients who become manifest at an earlier stage tend to have slower velocity saccades, and it has been suggested that those patients are more likely to have inherited the gene from their paternal side. ${ }^{93}$ Longitudinal studies of saccadic eye movements have reported significant progressive slowing and prolongation of reaction times and despite the great individual variation, impairment of the initial saccadic velocity is more prominent in younger patients. 100

All the findings mentioned above can be attributed to the malfunction in parallel pathways that are utilised for the various saccadic eye movement behaviours in different saccadic paradigms. As Hikosaka et $a l^{79}$ have described, a neurodegenerative disease affecting the frontal lobes or the caudate nucleus that inhibits the substantia nigra, pars reticulata (SNpr), the major outflow centre for saccades in the basal ganglia, may lead

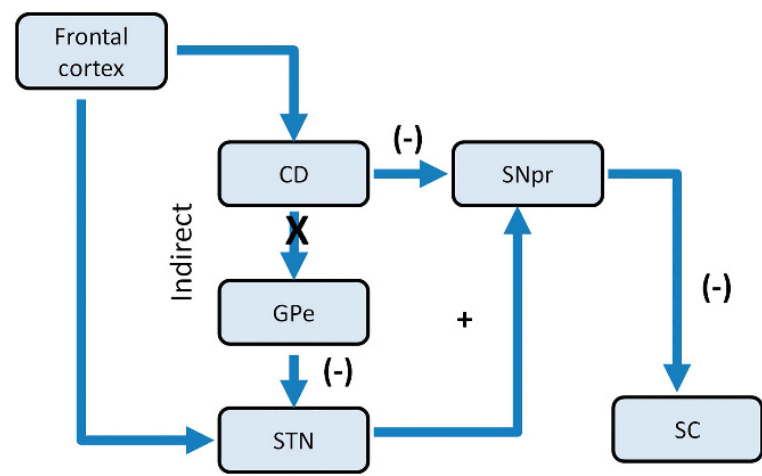

Figure 1 Schematic illustration showing two pathways projecting to superior colliculus (SC) via pars reticulate (SNpr), termed the direct and indirect pathways. Excitatory projections to the caudate from the frontal cortex trigger saccades via the indirect pathway. CD inhibits the SNpr, which tonically inhibits the SC. Excitation of $\mathrm{CN}$ could lead to disinhibition of SC and thus generation of saccades. The direct pathway may mediate saccade initiation by decreasing GABAergic connections within the SC. A possible mechanism by which HD interferes with saccades is by disruption of the indirect pathway as shown at the point marked $\mathrm{X} ;(-)$ inhibitory, + excitatory. to difficulties in initiating voluntary saccades in tasks that might require learned or predictive behaviour. Furthermore, HD also affects the $\mathrm{SNpr}^{101}$ and as the SNpr inhibits the superior colliculus (SC), it could therefore affect saccades to visual stimuli. Two distinct pathways project to the SC, working sequentially to suppress planned eye movements. One of them may be disrupted in HD as shown in Figure 1.

The strong correlation between the worsening of saccadic performance and disease severity, particularly in later stages of the disease, indicates that abnormalities in eye movements might be a useful and sensitive clinical marker not only in assessing motor and functional changes in HD individuals, but also in separating manifest from premanifest individuals.

\section{Conflict of interest}

The authors declare no conflict of interest.

\section{References}

1 Kennard C, Leigh RJ. Using Eye Movements as an Experimental Probe of Brain Function, Volume 171 Progress in Brain Research. Elsevier: Amsterdam, The Netherlands, 2008.

2 Antoniades CA, Xu Z, Mason SL, Carpenter RH, Barker RA. Huntington's disease: changes in saccades and hand-tapping over 3 years. J Neurol 2010; 257(11): 1890-1898.

3 Antoniades CA, Buttery P, Fitzgerald JJ, Barker RA, Carpenter RH, Watts C. Deep brain stimulation: eye movements reveal anomalous effects of electrode placement and stimulation. PLoS One 2012; 7(3): e32830.

4 Leigh RJ, Kennard C. Using saccades as a research tool in the clinical neurosciences. Brain 2004; 127: 460-477.

5 Leigh RJ, Zee DS. The Neurology of Eye Movements: New York. Oxford University Press, 2006.

6 Kaufman LD, Pratt J, Levine B, Black SE. Antisaccades: a probe into the dorsolateral prefrontal cortex in Alzheimer's disease. A critical review. J Alzheimers Dis 2010; 19(3): 781-793.

7 Hershey LA, Whicker Jr L, Abel LA, Dell'Osso LF, Traccis S, Grossniklaus D. Saccadic latency measurements in dementia. Arch Neurol 1983; 40(9): 592-593.

8 Fletcher WA, Sharpe JA. Saccadic eye movement dysfunction in Alzheimer's disease. Ann Neurol 1986; 20(4): 464-471.

9 Moser A, Kompf D, Olschinka J. Eye movement dysfunction in dementia of the Alzheimer type. Dementia 1995; 6(5): 264-268.

10 Lueck KL, Mendez MF, Perryman KM. Eye movement abnormalities during reading in patients with Alzheimer disease. Neuropsychiatry Neuropsychol Behav Neurol 2000; 13(2): 77-82.

11 Schewe HJ, Uebelhack R, Vohs K. Abnormality in saccadic eye movement in dementia. Eur Psychiatry 1999; 14(1): 52-53.

12 Mosimann UP, Muri RM, Burn DJ, Felblinger J, O'Brien JT, McKeith IG. Saccadic eye movement changes in 
Parkinson's disease dementia and dementia with Lewy bodies. Brain 2005; 128(Pt 6): 1267-1276.

13 Pirozzolo FJ, Hansch EC. Oculomotor reaction time in dementia reflects degree of cerebral dysfunction. Science 1981; 214(4518): 349-351.

14 Shafiq-Antonacci R, Maruff P, Masters C, Currie J. Spectrum of saccade system function in Alzheimer disease. Arch Neurol 2003; 60(9): 1272-1278.

15 Garbutt S, Matlin A, Hellmuth J, Schenk AK, Johnson JK, Rosen $\mathrm{H}$ et al. Oculomotor function in frontotemporal lobar degeneration, related disorders and Alzheimer's disease. Brain 2008; 131(Pt 5): 1268-1281.

16 Scinto LF, Daffner KR, Castro L, Weintraub S, Vavrik M, Mesulam MM. Impairment of spatially directed attention in patients with probable Alzheimer's disease as measured by eye movements. Arch Neurol 1994; 51(7): 682-688.

17 Abel LA, Unverzagt F, Yee RD. Effects of stimulus predictability and interstimulus gap on saccades in Alzheimer's disease. Dement Geriatr Cog Disord 2002; 13(4): 235-243.

18 Currie J, Ramsden B, McArthur C, Maruff P. Validation of a clinical antisaccadic eye movement test in the assessment of dementia. Arch Neurol 1991; 48(6): 644-648.

19 Garbutt S, Matlin A, Hellmuth J, Schenk AK, Johnson JK, Rosen $\mathrm{H}$ et al. Oculomotor function in frontotemporal lobar degeneration, related disorders and Alzheimer's disease. Brain 2008; 131(5): 1268-1281.

20 Crawford TJ, Higham S, Renvoize T, Patel J, Dale M, Suriya A et al. Inhibitory control of saccadic eye movements and cognitive impairment in Alzheimer's disease. Biological Psychiatry 2005; 57(9): 1052-1060.

21 Heuer HW, Mirsky JB, Kong EL, Dickerson BC, Miller BL, Kramer JH et al. Antisaccade task reflects cortical involvement in mild cognitive impairment. Neurology 2013; 81(14): 1235-1243.

22 Hutton JT, Nagel JA, Loewenson RB. Eye tracking dysfunction in Alzheimer-type dementia. Neurology 1984; 34(1): 99-102.

23 Fletcher WA, Sharpe JA. Smooth pursuit dysfunction in Alzheimer's disease. Neurology 1988; 38(2): 272-277.

24 Kapoula Z, Yang Q, Otero-Millan J, Xiao S, Macknik SL, Lang A et al. Distinctive features of microsaccades in Alzheimer's disease and in mild cognitive impairment. Age (Dordr) 2014; 36(2): 535-543.

25 Otero-Millan J, Macknik SL, Serra A, Leigh RJ, Martinez-Conde S. Triggering mechanisms in microsaccade and saccade generation: a novel proposal. Ann N Y Acad Sci 2011; 1233: 107-116.

26 Boxer AL, Miller BL. Clinical features of frontotemporal dementia. Alzheimer Dis Assoc Disord 2005; 19(Suppl 1): S3-S6.

27 Basun $\mathrm{H}$, Almkvist O, Axelman K, Brun A, Campbell TA, Collinge $\mathrm{J}$ et al. Clinical characteristics of a chromosome 17-linked rapidly progressive familial frontotemporal dementia. Arch Neurol 1997; 54(5): 539-544.

28 Neary D, Snowden JS, Gustafson L, Passant U, Stuss D, Black $\mathrm{S}$ et al. Frontotemporal lobar degeneration: a consensus on clinical diagnostic criteria. Neurology 1998 51(6): 1546-1554.

29 Meyniel C, Rivaud-Pechoux S, Damier P, Gaymard B. Saccade impairments in patients with fronto-temporal dementia. J Neurol Neurosurg Psychiatry 2005; 76(11): 1581-1584.
30 Boxer AL, Garbutt S, Rankin KP, Hellmuth J, Neuhaus J, Miller BL et al. Medial Versus Lateral Frontal Lobe Contributions to Voluntary Saccade Control as Revealed by the Study of Patients with Frontal Lobe Degeneration. J Neurosci 2006; 26(23): 6354-6363.

31 Burrell JR, Hornberger M, Carpenter RH, Kiernan MC, Hodges JR. Saccadic abnormalities in frontotemporal dementia. Neurology 2012; 78(23): 1816-1823.

32 Sha S, Hou C, Viskontas IV, Miller BL. Are frontotemporal lobar degeneration, progressive supranuclear palsy and corticobasal degeneration distinct diseases? Nat Clin Pract Neurol 2006; 2(12): 658-665

33 Boxer AL, Garbutt S, Seeley WW, Jafari A, Heuer HW, Mirsky J et al. Saccade abnormalities in autopsy-confirmed frontotemporal lobar degeneration and Alzheimer disease. Arch Neurol 2012; 69(4): 509-517.

34 Repka MX, Claro MC, Loupe DN, Reich SG. Ocular motility in Parkinson's disease. J Pediatr Ophthalmol Strabismus 1996; 33(3): 144-147.

35 DeJong JD, Jones GM. Akinesia, hypokinesia, and bradykinesia in the oculomotor system of patients with Parkinson's disease. Exp Neurol 1971; 32(1): 58-68.

36 Bronstein AM, Kennard C. Predictive ocular motor control in Parkinson's disease. Brain 1985; 108(Pt 4): 925-940.

37 Shibasaki H, Tsuji S, Kuroiwa Y. Oculomotor abnormalities in Parkinson's disease. Arch Neurol 1979; 36(6): 360-364.

38 White OB, Saint-Cyr JA, Tomlinson RD, Sharpe JA. Ocular motor deficits in Parkinson's disease. II. Control of the saccadic and smooth pursuit systems. Brain 1983; 106(Pt 3): 571-587.

39 Rascol O, Clanet M, Montastruc JL, Simonetta M, Soulier-Esteve MJ, Doyon B et al. Abnormal ocular movements in Parkinson's disease. Evidence for involvement of dopaminergic systems. Brain 1989; 112(Pt 5): 1193-1214.

40 Muller C, Wenger S, Fertl L, Auff E. Initiation of visualguided random saccades and remembered saccades in parkinsonian patients with severe motor-fluctuations. J Neur Transm 1994; 7(2): 101-108.

41 Rottach KG, Riley DE, DiScenna AO, Zivotofsky AZ, Leigh RJ. Dynamic properties of horizontal and vertical eye movements in parkinsonian syndromes. Ann Neurol 1996; 39(3): 368-377.

42 Highstein S, Cohen B, Mones R. Changes in saccadic eye movements of patients with Parkinson's disease before and after L-dopa. Trans Am Neurol Assoc 1969; 94: 277-279.

43 Teravainen H, Calne DB. Studies of parkinsonian movement: 2. Initiation of fast voluntary eye movement during postural disturbance. Acta Neurol Scand 1980; 62(3): 149-157.

44 Crawford T, Goodrich S, Henderson L, Kennard C. Predictive responses in Parkinson's disease: manual keypresses and saccadic eye movements to regular stimulus events. J Neurol Neurosurg Psychiatry 1989; 52(9): 1033-1042.

45 Ventre J, Zee DS, Papageorgiou H, Reich S. Abnormalities of predictive saccades in hemi-Parkinson's disease. Brain 1992; 115(Pt 4): 1147-1165.

46 Crawford TJ, Henderson L, Kennard C. Abnormalities of nonvisually-guided eye movements in Parkinson's disease. Brain 1989; 112(Pt 6): 1573-1586.

47 Lueck CJ, Tanyeri S, Crawford TJ, Henderson L, Kennard C. Antisaccades and remembered saccades in 
Parkinson's disease. J Neurol Neurosurg Psychiatry 1990; 53(4): 284-288.

48 Crevits L, De Ridder K. Disturbed striatoprefrontal mediated visual behaviour in moderate to severe parkinsonian patients. J Neurol Neurosurg Psychiatry 1997; 63(3): 296-299.

49 Vermersch AI, Rivaud S, Vidailhet M, Bonnet AM, Gaymard B, Agid Y et al. Sequences of memory-guided saccades in Parkinson's disease. Ann Neurol 1994; 35(4): 487-490.

50 Armstrong IT, Chan F, Riopelle RJ, Munoz DP. Control of saccades in Parkinson's disease. Brain Cogn 2002; 49(2): 198-201.

51 MacAskill MR, Anderson TJ, Jones RD. Adaptive modification of saccade amplitude in Parkinson's disease. Brain 2002; 125(Pt 7): 1570-1582.

52 Winograd-Gurvich C, Georgiou-Karistianis N, Fitzgerald PB, Millist L, White OB. Self-paced saccades and saccades to oddball targets in Parkinson's disease. Brain Res 2006; 1106(1): 134-141.

53 Chan F, Armstrong IT, Pari G, Riopelle RJ, Munoz DP. Deficits in saccadic eye-movement control in Parkinson's disease. Neuropsychologia 2005; 43(5): 784-796.

54 Hodgson TL, Bajwa A, Owen AM, Kennard C. The strategic control of gaze direction in the Tower-of-London task. J Cogn Neurosci 2000; 12(5): 894-907.

55 Kennard C. Scanpaths: the path to understanding abnormal cognitive processing in neurological disease. Ann N Y Acad Sci 2002; 956: 242-249.

56 Kitagawa M, Fukushima J, Tashiro K. Relationship between antisaccades and the clinical symptoms in Parkinson's disease. Neurology 1994; 44(12): 2285-2289.

57 Dubois B, Pillon B, Sternic N, Lhermitte F, Agid Y. Age-induced cognitive disturbances in Parkinson's disease. Neurology 1990; 40(1): 38-41.

58 Vidailhet M, Rivaud S, Gouider-Khouja N, Pillon B, Bonnet AM, Gaymard B et al. Eye movements in parkinsonian syndromes. Ann Neurol 1994; 35(4): 420-426.

59 Briand KA, Strallow D, Hening W, Poizner H, Sereno AB. Control of voluntary and reflexive saccades in Parkinson's disease. Exp Brain Res 1999; 129(1): 38-48.

60 Amador SC, Hood AJ, Schiess MC, Izor R, Sereno AB. Dissociating cognitive deficits involved in voluntary eye movement dysfunctions in Parkinson's disease patients. Neuropsychologia 2006; 44(8): 1475-1482.

61 Rivaud-Pechoux S, Vidailhet M, Brandel JP, Gaymard B. Mixing pro- and antisaccades in patients with parkinsonian syndromes. Brain 2007; 130(Pt 1): 256-264.

62 Michell AW, Xu Z, Fritz D, Lewis SJ, Foltynie T, Williams-Gray $\mathrm{CH}$ et al. Saccadic latency distributions in Parkinson's disease and the effects of L-dopa. Exp Brain Res 2006; 174(1): 7-18.

63 Yugeta A, Terao Y, Fukuda H, Ugawa Y. Effects of levodopa on saccade performance in Parkinson's disease. Mov Disord 2008; 23(Suppl 1): S296.

64 Hood AJ, Amador SC, Cain AE, Briand KA, Al-Refai AH, Schiess MC et al. Levodopa slows prosaccades and improves antisaccades: An eye movement study in Parkinson's disease. J Neurol Neurosurg Psychiatry 2007; 78: 565-570.

65 Temel Y, Visser-Vandewalle V, Carpenter RH. Saccadometry: a novel clinical tool for quantification of the motor effects of subthalamic nucleus stimulation in Parkinson's disease. Exp Neurol 2009; 216(2): 481-489.
66 Sauleau P, Pollak P, Krack P, Courjon JH, Vighetto A, Benabid AL et al. Subthalamic stimulation improves orienting gaze movements in Parkinson's disease. Clin Neurophysiol 2008; 119(8): 1857-1863.

67 Yugeta A, Terao Y, Fukuda H, Hikosaka O, Yokochi F, Okiyama R et al. Effects of STN stimulation on the initiation and inhibition of saccade in Parkinson disease. Neurology 2010; 74(9): 743-748.

68 Rivaud-Pechoux S, Vermersch AI, Gaymard B, Ploner CJ, Bejjani BP, Damier P et al. Improvement of memory guided saccades in parkinsonian patients by high frequency subthalamic nucleus stimulation. J Neurol Neurosurg Psychiatry 2000; 68(3): 381-384.

69 Straube A, Ditterich J, Oertel W, Kupsch A. Electrical stimulation of the posteroventral pallidum influences internally guided saccades in Parkinson's disease. J Neurol 1998; 245(2): 101-105.

70 Wark HAC, Garell PC, Walker AL, Basso MA. A case report on fixation instability in Parkinson's disease with bilateral deep brain stimulation implants. J Neurol Neurosurg Psychiatry 2008; 79(4): 443-447.

71 O'Sullivan JD, Maruff P, Tyler P, Peppard RF, McNeill P, Currie J. Unilateral pallidotomy for Parkinson's disease disrupts ocular fixation. J Clin Neurosci 2003; 10(2): 181-185.

72 Cordato NJ, Halliday GM, McCann H, Davies L, Williamson P, Fulham M et al. Corticobasal syndrome with tau pathology. Mov Disord 2001; 16(4): 656-667.

73 Averbuch-Heller L, Helmchen C, Horn AK, Leigh RJ, Buttner-Ennerver JA. Slow vertical saccades in motor neuron disease: correlation of structure and function. Ann Neurol 1998; 44(4): 641-648.

74 Wenning GK, Jellinger K, Litvan I. Supranuclear gaze palsy and eyelid apraxia in postencephalitic parkinsonism. J Neural Transm 1997; 104(8-9): 845-865.

75 Grant MP, Cohen M, Petersen RB, Halmagyi GM, McDougall A, Tusa RJ et al. Abnormal eye movements in Creutzfeldt-Jakob disease. Ann Neurol 1993; 34(2): 192-197.

76 Rinne JO, Lee MS, Thompson PD, Marsden CD. Corticobasal degeneration. A clinical study of 36 cases. Brain 1994; 117(Pt 5): 1183-1196.

77 Antoniades CA, Carpenter RS, Barker RA. Diagnostic potential of saccadometry in progressive supranuclear palsy. Biomark Med 2007; 1(4): 487-490.

78 Leigh RJ, Newman SA, Folstein SE, Lasker AG, Jensen BA. Abnormal ocular motor control in Huntington's disease. Neurology 1983; 33(10): 1268-1275.

79 Hikosaka O, Takikawa Y, Kawagoe R. Role of the basal ganglia in the control of purposive saccadic eye movements. Physiol Rev 2000; 80(3): 953-978.

80 Hikosaka O. Basal Ganglia Mechanisms of Rewardoriented Eye Movement. Ann N Y Acad Sci 2007; 1104: 229-249.

81 Starr A. A disorder of rapid eye movements in Huntington's chorea. Brain 1967; 90(3): 545-564.

82 Collewijn H, Went LN, Tamminga EP, Vegter-Van der Vlis M. Oculomotor defects in patients with Huntington's disease and their offspring. J Neurol Sci 1988; 86(2-3): 307-320.

83 Rothlind JC, Brandt J, Zee D, Codori AM, Folstein S. Unimpaired verbal memory and oculomotor control in asymptomatic adults with the genetic marker for Huntington's disease. Arch Neurol 1993; 50(8): 799-802. 
84 Golding CVP, Danchaivijitr C, Hodgson TL, Tabrizi SJ, Kennard C. Identification of an oculomotor biomarker of preclinical Huntington disease. Neurology 2006; 67: 485-487.

85 Blekher TJS, Marshall J, White K, Hui S, Weaver M, Gray J et al. Saccades in presymptomatic and early stages of Huntington disease. Neurology 2006; 67: 394-399.

86 Antoniades CA, Altham PM, Mason SL, Barker RA, Carpenter R. Saccadometry: a new tool for evaluating presymptomatic Huntington patients. Neuroreport 2007; 18(11): 1133-1136.

87 Siemers E, Foroud T, Bill DJ, Sorbel J, Norton Jr JA, Hodes ME et al. Motor changes in presymptomatic Huntington disease gene carriers. Arch Neurol 1996; 53(6): 487-492.

88 Kirkwood SC, Siemers E, Bond C, Conneally PM, Christian JC, Foroud T. Confirmation of subtle motor changes among presymptomatic carriers of the Huntington disease gene. Arch Neurol 2000; 57(7): 1040-1044.

89 Kirkwood SC, Siemers E, Hodes ME, Conneally PM, Christian JC, Foroud T. Subtle changes among presymptomatic carriers of the Huntington's disease gene. J Neurol Neurosurg Psychiatry 2000; 69(6): 773-779.

90 Bollen E, Reulen JP, Den Heyer JC, Van der Kamp W, Roos RA, Buruma OJ. Horizontal and vertical saccadic eye movement abnormalities in Huntington's chorea. J Neurol Sci 1986; 74(1): 11-22.

91 Lasker AG, Zee DS, Hain TC, Folstein SE, Singer HS. Saccades in Huntington's disease: initiation defects and distractibility. Neurology 1987; 37(3): 364-370.
92 Peltsch A, Hoffman A, Armstrong I, Pari G, Munoz DP. Saccadic impairments in Huntington's disease. Exp Brain Res 2008; 186(3): 457-469.

93 Lasker AG, Zee DS, Hain TC, Folstein SE, Singer HS. Saccades in Huntington's disease: slowing and dysmetria. Neurology 1988; 38(3): 427-431.

94 Tian JR, Zee DS, Lasker AG, Folstein SE. Saccades in Huntington's disease: predictive tracking and interaction between release of fixation and initiation of saccades. Neurology 1991; 41(6): 875-881.

95 Lasker AG, Zee DS. Ocular motor abnormalities in Huntington's disease. Vis Res 1997; 37(24): 3639-3645.

96 Lasker G, Adrian ZD. Ocular Motor abnormalities in Huntington's disease. Vis Res 1997; 37(24): 3639-3645.

97 Blekher TM, Yee RD, Kirkwood SC, Hake AM, Stout JC, Weaver MR et al. Oculomotor control in asymptomatic and recently diagnosed individuals with the genetic marker for Huntington's disease. Vis Res 2004; 44: 2729-2736.

98 Ali FR, Michell AW, Barker RA, Carpenter RH. The use of quantitative oculometry in the assessment of Huntington's disease. Exp Brain Res 2006; 169(2): 237-245.

99 Avanzini G, Girotti F, Caraceni T, Spreafico R. Oculomotor disorders in Huntington's chorea. J Neurol Neurosurg Psychiatry 1979; 42(7): 581-589.

100 Rubin AJ, King WM, Reinbold KA, Shoulson I. Quantitative longitudinal assessment of saccades in Huntington's disease. J Clin Neuro Ophthalmol 1993; 13(1): 59-66.

101 Oyanagi K, Takeda S, Takahashi H, Ohama E, Ikuta F. A quantitative investigation of the substantia nigra in Huntington's disease. Ann Neurol 1989; 26(1): 13-19. 